Disponível em

http://www.anpad.org.br/rac

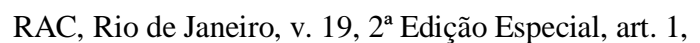
pp. 117-136, Agosto 2015

http://dx.doi.org/10.1590/1982-7849rac20151507

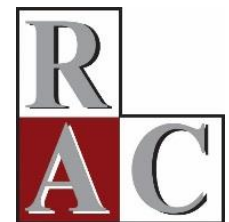

$((c)$ EY

\title{
Constituição de uma Comunidade Virtual de Marca no Lançamento de Novo Produto
}

\author{
Building a Brand Community Online During a New Product Launch
}

Maribel Carvalho Suarez

Universidade Federal do Rio de Janeiro - UFRJ

Flavia Luzia Oliveira da Cunha Galindo Universidade Federal Rural do Rio de Janeiro - UFRRJ

Vaclav Soukup Filho Universidade Federal do Rio de Janeiro - UFRJ

Rafael Machado

Universidade Federal do Rio de Janeiro - UFRJ 


\title{
Resumo
}

A presente pesquisa analisa o processo de formação de uma comunidade em torno de uma marca antes do seu efetivo lançamento no mercado. Para isso, utilizou-se o método netnográfico para investigar uma comunidade automotiva criada meses antes da chegada do automóvel às ruas. O trabalho sugere a busca por informações e o desejo de influenciar o desenho da nova oferta, como fatores a mobilizar os consumidores em torno da comunidade. O envolvimento com a categoria, o posicionamento aspiracional da marca corporativa e a expectativa de mudanças a partir desse lançamento também se mostraram como aspectos relevantes na constituição do grupo. O trabalho sugere uma tipologia de membros a partir de duas dimensões: a informação sobre a categoria e a experiência de uso com a marca/modelo em questão. A tipologia distingue novatos (baixa informação e baixa experiência), teóricos (alta informação e baixa experiência), pragmáticos (baixa informação e alta experiência) e experts (alta informação e alta experiência) e evidencia lógicas que hierarquizam as interações entre os membros, ajudando a explicar as dinâmicas e o processo de evolução da comunidade.

Palavras-chave: comunidades de marca; automóveis; netnografia; Hyundai; HB20.

\begin{abstract}
This article presents an investigation of the building process of an online brand-associated community. It uses netnographic methods to investigate an automotive community, created months before a new model was actually launched. The study highlights the motivation to gather information and to influence product launch as factors to mobilize community existence. Category involvement, aspirational positioning of the corporate brand and revolutionary promises for this product also seem to be relevant to promote the community. The research presents a typology of community members based on two dimensions: information about the category and user experience with the brand/model. The typology distinguishes between newbies (low information and low experience), theoretical (high information and low experience), pragmatic (low information and high experience) and experts (high information and high experience). The paper highlights logics that stratify members' interactions, explaining community formation dynamics and evolution processes.
\end{abstract}

Key words: brand communities; automobile; netnography; Hyundai; HB20. 


\section{Introdução}

As comunidades de marca tornaram-se tópico fundamental no marketing contemporâneo (Cova \& White, 2010). Definidas inicialmente como agrupamentos especializados, não geograficamente definidos, mas tendo como base um conjunto estruturado de relações sociais entre os admiradores de uma marca (Muñiz \& O`Guinn, 2001), esse tema vem sendo amplamente estudado por sua relevância para as empresas.

Diversos trabalhos evidenciam as comunidades de marca como elemento de socialização e empoderamento dos consumidores (Cova \& Pace, 2006) que potencializa o boca a boca (Kozinets, Valck, Wojnicki, \& Wilner, 2010; Yeh \& Choi, 2011) e o compartilhamento de experiências de consumo (Almeida \& Ramos, 2012; Scaraboto, Vargas, \& Costa, 2012; Schellekens, Verlegh, \& Smidts, 2010; Ward \& Ostrom, 2006).

Trabalhos recentes têm levado à ampliação do seu próprio conceito. Muñiz e Schau (2005) evidenciaram que as comunidades de marca podem ser constituídas à revelia dos interesses da própria empresa. Cova e White (2010) destacam como esses agrupamentos de consumidores também podem desenvolver ofertas que competem com os bens e serviços empresariais. Autores como Kozinets e Handelman (2004) e Hollenbeck e Zinkhan (2010), por sua vez, investigaram como as comunidades podem se constituir não em torno, mas contra uma marca, em comportamentos de anticonsumo.

Um aspecto inerente a esses e a outros tantos estudos no campo de comportamento do consumidor diz respeito à existência de uma marca a partir da qual os consumidores possam se posicionar e constituir relações sociais. A presente pesquisa contribui com esse tema com a investigação de um contexto ainda inexplorado no campo: o processo de formação de uma comunidade de marca em torno de uma oferta que sequer havia chegado ao mercado. Para isso, utiliza-se a abordagem qualitativa, a partir da netnografia (Kozinets, 2010), a fim de investigar uma comunidade que se reúne meses antes do lançamento do modelo HB20, da Hyundai. Assim, o objetivo da presente pesquisa é entender a constituição desse agrupamento de consumidores na internet em torno não de uma oferta existente, mas de uma marca em construção. O estudo busca analisar as dinâmicas de criação de hierarquias e valores nesse período inicial de formação da comunidade, bem como os elementos que foram capazes de congregar consumidores.

\section{Referencial Teórico}

Diversos estudos destacam a importância simbólica dos automóveis (Belk, 2004; Hirschman, 2003; Luedicke \& Giesler, 2008), como uma categoria que envolve um longo processo decisório (Hernandez, 2002; Sastre, Serralvo, \& Moras, 2010; Zhu, Chen, \& Dasgupta, 2008) e é capaz de despertar intensas emoções (Desmet, Hekkert, \& Jacobs, 2000; Luce, 1998).

Hirschman (2003) aponta a associação entre automóveis e as características humanas, valores e objetivos de seus donos, tais como força, maldade, dureza. Belk (2004) estudou consumidores com alto nível de envolvimento com o produto, os chamados entusiastas. $\mathrm{O}$ autor, através desse grupo, ressalta a importância desse bem e sua associação com significados como força, perigo, mobilidade, status, competição e dominação do homem sobre a natureza. Para esses consumidores, carros são, ao mesmo tempo, seres animados e uma extensão de si próprios.

Por meio do estudo das discussões das comunidades da internet em torno do lançamento do novo fusca, Brown, Kozinets e Sherry (2003) mostram a capacidade da categoria de mobilizar significados ideológicos (como um carro democrático, impregnado dos valores do movimento hippie, como o sonho de melhores condições espirituais e materiais para a humanidade). Ao investigar a marca Hummer, Luedicke (2006) também destaca que mais do que gerar diferenciação em termos de classe social (classe 
alta) e estilo de vida (estereótipos atléticos, de masculinidade, de sucesso e fama), a posse do automóvel é capaz de mobilizar o conceito de patriotismo. Luedicke e Giesler (2008), por sua vez, evidenciam como a categoria de automóveis é capaz de suscitar o que os autores chamam de consumo contestado que se refere à elaboração de discursos que contestam a legitimidade de escolhas, comportamentos e ideologias de outros consumidores.

No contexto brasileiro, DaMatta, Vasconcelos e Pandolfi (2010) consolidam o automóvel como artefato que tangibiliza a norma aristocrática que permeia o sistema social brasileiro. Para os autores, ele se tornou, no Brasil, um meio de diferenciação dos indivíduos, que podem ser hierarquizados a partir de aspectos relacionados ao preço e à marca do veículo. Suarez, Chauvel e Casotti (2012) também corroboram a importância simbólica desse produto no Brasil, não pela perspectiva do consumo, mas através da investigação a respeito do abandono dessa categoria. As autoras salientam o abandono do automóvel como movimento simbólico capaz de operar diferenciação afirmativa, positiva e de reforço da autoestima, assim, constituindo identidades como a do consumidor moderno, descolado, artista, atleta, consciente, responsável ou engajado.

\section{Comunidades virtuais de marca}

A internet tem sido o ambiente por meio do qual comunidades estruturadas em torno de interesses comuns de consumo têm se formado e propagado rapidamente (Muñiz \& Schau, 2005; Schau, Muñiz, \& Arnould, 2009). Uma definição seminal, ainda amplamente aceita, para as comunidades on-line foi proposta por Rheingold (1993) como "agregações sociais que emergem da internet quando pessoas em número suficiente se envolvem em discussões públicas longas o bastante, como o devido envolvimento emocional para formar redes de relacionamento pessoal no ciberespaço" (p. 5). De maneira mais específica, as comunidades de marca se constituem como um conjunto de relações sociais em torno de uma marca (Muñiz \& O’Guinn, 2001). Segundo os autores, os valores de ligação que unem esses consumidores transcendem barreiras geográficas, culturais, demográficas, raciais, étnicas e até diferenças de classe. Podendo se constituir tanto dentro quanto fora da internet, as comunidades de marca encontraram no ambiente virtual um lugar propício para o seu desenvolvimento.

Muñiz e O’Guinn (2001) apresentam as características essenciais das comunidades de marca, que também estão presentes nas comunidades clássicas: consciência compartilhada; rituais e tradições; e um senso de responsabilidade moral. Estudos recentes nos oferecem reflexões a respeito de como essas três características se formam, moldando o desenvolvimento e as ações dentro de uma comunidade.

A consciência compartilhada diz respeito tanto ao desenvolvimento da dimensão cognitiva da identidade social quanto à afetiva, fazendo com que os participantes apresentem envolvimento emocional com o grupo (Algesheimer, Dholakia, \& Herrmann, 2005; Muñiz \& O’Guinn, 2001). Investigando o desenvolvimento de relações em uma comunidade on-line, Kozinets (2010) destaca que, ao mesmo tempo em que as informações baseadas em fatos são passadas, as pessoas acabam aprendendo sobre a própria comunidade, sua linguagem, normas, valores, rituais, práticas, preferências e seus líderes e membros. Conforme detalhes pessoais são compartilhados, amadurece uma coesão cultural e surge a empatia, enquanto vai sendo aprendida a estrutura de poder do grupo e o status dos relacionamentos.

Muñiz e O'Guinn (2001) explicitam mais detalhadamente dois processos através dos quais a consciência compartilhada é constituída em comunidades de marca: a legitimação e a lealdade oposicional à marca. No primeiro processo, os indivíduos membros da comunidade começam a diferenciar-se a partir da frequência de interação e tempo de participação na comunidade, constituindo uma hierarquização. Já a lealdade oposicional fomenta a consciência compartilhada ao unir a comunidade em torno de um adversário poderoso. S. A. Thompson e Sinha (2008) evidenciam que essa dinâmica reduz inclusive a probabilidade de compra de marcas concorrentes.

O`Sullivan, Richardson e Collins (2011) sugerem que a consciência compartilhada surge a partir de uma experiência de conversão, que faz com que os indivíduos percebam qualidades sagradas na marca em questão. A conversão estaria relacionada a uma experiência integradora e transcendente com 
a marca, ligada ao autoconceito dos consumidores. Os autores identificaram ainda que a fiscalização social da lealdade à marca também seria uma forma de manter a consciência de grupo.

Os rituais e tradições representam processos sociais vitais nos quais os significados da comunidade são reproduzidos e transmitidos dentro e fora dela. De acordo com Muñiz e O’Guinn (2001), eles se constituem principalmente a partir da celebração da história da marca e do compartilhamento de histórias dos integrantes da comunidade (algo que, por sua vez, reforça a consciência compartilhada entre os membros). Ao descrever diferentes tipos de práticas das comunidades on-line, Schau, Muñiz e Arnould (2009) também nos oferecem alguns exemplos de práticas que podem ser entendidas como rituais, ou seja, como exemplos de ação social dedicada à manipulação do significado cultural, para propósitos de comunicação e categorização coletiva e individual (McCracken, 2003). Segundo os autores, as práticas de gerenciamento de impressão são aquelas que têm um foco externo na criação de impressões favoráveis para a marca, seus entusiastas e sua comunidade, incluindo a evangelização e a justificação. A evangelização está relacionada ao compartilhamento de boas notícias sobre a marca e na inspiração que os membros dão uns aos outros para usá-la. Já a justificação é a racionalização do tempo e esforço gastos na marca (Schau et al., 2009).

As práticas de engajamento inventariadas pelos autores também apresentam clara dimensão ritual, reforçando a escala de comprometimento dos membros com a comunidade. Schau et al. (2009) dividem o engajamento em quatro subcategorias: a delimitação, os marcos, as insígnias e a documentação. A delimitação ocorre quando é reconhecida a variância existente entre os membros, marcando as distinções e as similaridades entre o grupo; o marco é a prática de notar eventos seminais no consumo e na posse da marca; as insígnias são a transformação dos marcos em símbolos; e a documentação é o detalhamento do relacionamento com a marca de uma forma narrativa, geralmente contada a partir dos marcos.

As práticas de uso da marca também apresentam certa dimensão ritual. Elas são especificamente relacionadas com a melhoria ou aumento do uso da marca em foco. Incluem práticas de cuidado, customização e comoditização. $\mathrm{O}$ cuidado é referente às atividades de proteção da marca ou sistematização do uso ideal; a customização é quando a marca é modificada para atender às necessidades individuais ou de um nível do grupo, em um esforço para melhorar a performance do produto. Por fim, a comoditização diz respeito ao distanciamento/aproximação do mercado; é a valoração de práticas comerciais, que pode ser destinada a outro membro (ex.: você deve/não deve vender isso) ou às empresas (ex.: você deve consertar isso/fazer isso/mudar isso).

De acordo com Muñiz e O’Guinn (2001), o terceiro aspecto fundamental na constituição de uma comunidade estaria na existência de um senso de responsabilidade moral. Este é a percepção, por parte dos membros, de que há um dever a ser cumprido em relação àquela comunidade. A responsabilidade moral pode ser percebida em pelo menos duas missões da comunidade: integração e retenção de membros e assistência aos membros da comunidade quanto à maneira correta de utilizá-la (Muñiz \& O’Guinn, 2001). Schau et al. (2009) nos oferecem alguns exemplos de práticas de relacionamento social, que podem ser associadas ao senso de responsabilidade moral. As boas-vindas ocorrem quando novos membros são recebidos na comunidade ou em novas práticas. A empatia acontece quando é dado apoio emocional ou físico a outros membros. Já as práticas de administração dizem respeito à articulação das expectativas de comportamento na comunidade.

A investigação sobre um grupo constituído em torno de uma oferta antes mesmo do seu lançamento permite ampliar o conhecimento a respeito das comunidades de marca, problematizando uma de suas principais premissas: a de que elas se constituem a partir dos significados da marca e da capacidade desta em mobilizar identidades compartilhadas pelos consumidores. A presente pesquisa permite aprofundar essa discussão indo além da dimensão simbólica da marca, para incorporar aspectos relacionados à categoria, às condições de mercado e às relações entre consumidores e empresa como elementos cruciais para a compreensão das motivações de criação e desenvolvimento de uma comunidade de marca. 


\section{Metodologia}

A presente pesquisa utilizou-se de abordagem qualitativa e dos procedimentos fundamentais da netnografia para a investigação da comunidade HB20. Como uma adaptação do tradicional método etnográfico aplicado ao estudo de comunidades e cultura on-line, a netnografia apresenta-se como um método reconhecido e consolidado dentro do campo de comportamento do consumidor (Kozinets, 2010). O método adapta os procedimentos etnográficos - como fazer entrée cultural, coletar dados, analisá-los e interpretá-los - para as contingências da realidade on-line, em que se manifestam através da comunicação mediada por computador (Kozinets, 2010).

Este trabalho se insere em um projeto mais amplo de investigação das marcas asiáticas no contexto da internet. Para isso, foram selecionados fóruns em que o consumo de automóvel fosse o tema aglutinador dos internautas. Segundo Kozinets (2010), fóruns e listas são uma das mais antigas e ricas formas de comunidades on-line. São trocas de e-mails ou posts baseados em texto (podendo também conter imagens), organizados em torno de orientações ou interesses particulares em comum. Os participantes publicam mensagens ou comentários que podem ser respondidos de forma assíncrona pelos outros membros do grupo. Numa fase inicial, além da comunidade HB20, foram investigadas também outras comunidades relacionadas à marca Hyundai (dos modelos Azera e I30). Essa atividade exploratória foi fundamental para comparar e contextualizar os resultados da presente pesquisa.

O fórum da HB20 foi escolhido para uma análise mais profunda e continuada por sua singularidade, por se tratar de uma congregação de indivíduos em torno da marca de um produto em pré-lançamento no mercado brasileiro, no momento inicial da pesquisa. Além dessa relevância, esse fórum mostrou-se adequado a diversos critérios propostos por Kozinets (2010) para a pesquisa netnográfica: (a) interatividade (intensidade da relação entre os membros da comunidade e articulação e promoção da comunicação entre eles para a construção de diálogos, criando elos e cultura compartilhada); (b) substância (possuir pessoas suficientes e ativas para gerarem conteúdo expressivo); (c) heterogeneidade (comunidade que aceita membros de origens variadas, com diferentes posicionamentos, que revelam uma natureza desigual e participativa); (d) riqueza de informações, sendo capaz de permitir debates com discursos aparentemente incoerentes sobre o mesmo tema, evidenciando a pluralidade de atores e de posicionamentos, em seus diferentes graus de informação. Para a realização dessa pesquisa foi obtida a aprovação do administrador do fórum.

Foram analisados aproximadamente 700 posts publicados entre os meses de agosto de 2012 e abril de 2013, totalizando quase 350 páginas de material a ser analisado. Dado o objetivo da presente pesquisa - analisar as dinâmicas de criação de hierarquias e valores nesse período inicial de formação da comunidade em torno de uma marca em construção, a coleta de dados foi encerrada a partir do entendimento de que a comunidade havia alcançado certa estabilidade. Tal aspecto foi evidenciado pela existência de clara diferenciação dos seus integrantes, a existência e repetição de práticas rituais, a consolidação (pela repetição) dos valores do grupo e o senso de responsabilidade moral. Assim, a coleta de dados foi finalizada quando os pesquisadores julgaram que a comunidade HB20 se tornara semelhante no que diz respeito a esses conceitos a grupos estudados por outros autores (Muñiz \& O’Guinn, 2001; Schau et al., 2009) e também às comunidades em torno dos modelos Azera e I30 (marcas consolidadas da Hyundai, investigadas pelos pesquisadores na fase inicial da pesquisa).

Não houve a elaboração de um roteiro prévio de observação e análise, sendo estas guiadas pelas próprias dinâmicas da comunidade (por exemplo, posts mais populares ou polêmicos, temas de maior interesse do grupo, transformações na estrutura do fórum, emergência de novos comportamentos, etc.). A análise desenvolveu-se a partir do trabalho de descrição das interações e codificação dos principais posts selecionados a partir da leitura e acompanhamento das discussões no grupo. A codificação englobou atividades como atribuir palavras-chave/códigos aos posts e refinar e analisar a relação entre esses rótulos, buscando encontrar novos significados e alcançar níveis mais abstratos, permitindo gerar interpretações e conceitos que serão apresentados a seguir (Miles, Huberman, \& Saldaña, 2013). Diversos códigos foram sugeridos pela literatura existente, outros emergiram dos próprios dados. A 
análise utilizou-se ainda do processo hermenêutico na interpretação dos dados (C. J. Thompson, Pollio, \& Locander, 1994), buscando entender o significado dos posts a partir da referência ao todo, ou seja, a comunidade a que faziam parte.

\section{Análise dos Resultados}

O presente trabalho se insere em um projeto de pesquisa mais amplo, que incluiu a investigação de outras duas comunidades associadas às marcas Hyundai. Assim, além do fórum da HB20, foram investigadas comunidades relacionadas aos modelos Azera e I30.

A Hyundai é uma das cinco maiores fabricantes de carros do mundo. De origem sul-coreana, está instalada no Brasil desde o final da década de 1990. Em abril de 2007, a empresa inaugurou sua primeira fábrica brasileira, na cidade de Anápolis (GO), e, em 2012, abriu a nova planta de Piracicaba (SP), onde fabrica os modelos HB. O HB20 foi desenvolvido pela empresa para o mercado brasileiro e representa a primeira incursão da Hyundai no chamado segmento popular (carros até $2000 \mathrm{cc}$, em valores até $\mathrm{R} \$ 40$ mil). No seu lançamento, o HB20 foi apresentado como o posicionamento de modern premium, como um luxo acessível à maioria, tendo versões que custavam de $\mathrm{R} \$ 34$ mil a $\mathrm{R} \$ 48$ mil (Quatro Rodas, 2013).

Nos últimos anos, a montadora tem se destacado na arena competitiva brasileira pelos altos investimentos publicitários. Segundo levantamento do Instituto Brasileiro de Opinião Pública e Estatística (Ibope, 2013), a Hyundai foi a maior anunciante do setor automotivo brasileiro, em 2012, investindo quase um bilhão de reais em publicidade. No segmento de veículos leves, a empresa adotava uma estratégia que privilegiava os estratos mais sofisticados. Depois do HB20, o modelo mais acessível da empresa, o SUV Tucson, custava aproximadamente R $\$ 63$ mil (Quatro Rodas, n.d.). Os demais produtos do portfólio brasileiro eram, em escala ascendente de valor: I30, Veloster, Elantra, Sonata, IX35, Santa Fé, Azera, Vera Cruz, Genesis e Equus - esse último com preço em torno de R \$290 mil (Quatro Rodas, n.d.).

Em 2011, a Hyundai deteve aproximadamente 3\% de participação no mercado brasileiro. Entretanto o lançamento do HB20, em outubro de 2012, apontou para uma tendência de aumento desse share, tendo a empresa alcançado, em novembro de 2012, 4,5\% de participação. O lançamento se revelou um grande sucesso de vendas, e, em março de 2013, o HB20 já despontava como o $4^{\circ}$ modelo mais vendido no país, atrás apenas do Gol, do Palio e do Uno (Federação Nacional da Distribuição de Veículos Automotores [Fenabrave], 2013).

Com o objetivo de contextualizar e colocar em perspectiva as características e achados relacionados ao fórum da HB20, foco do presente artigo, analisaremos brevemente alguns aspectos fundamentais presentes nas comunidades investigadas, como forma de contextualizar os insights proporcionados pela investigação do fórum da HB20.

\section{As comunidades automotivas na internet}

No levantamento inicial das comunidades relacionadas ao setor automotivo, um aspecto que chamou a atenção foi o fato de que os fóruns se organizam em torno da estrutura estabelecida pela indústria automotiva, espelhando o posicionamento projetado pelas montadoras a partir dos seus modelos. Assim, encontramos grupos mais ativos à volta de marcas e modelos de automóveis (por exemplo, proprietários e interessados na marca I30, HB20, Azera, QQ, Lifan320, Gol, Stilo, Palio, etc.) e não organizados a partir de necessidades específicas, condições demográficas ou temas técnicos e mais genéricos (por exemplo, hipoteticamente, proprietários de veículos 1.0 ou do primeiro automóvel ou, ainda, de carro velho). Nesse sentido, as marcas de automóveis, no contexto brasileiro, parecem servir como plataforma para interação e coesão social (Cova \& White, 2010; Kozinets et al., 2010; Schau et al., 2009). 
Outro aspecto comum às comunidades virtuais analisadas diz respeito ao fato de elas reunirem indivíduos que têm interesses nos modelos e marcas, e não apenas compradores efetivos. Assim, nesse tipo de congregação virtual, estão internautas que já compraram um carro e compartilham suas experiências de uso, mas, também, outros que orbitam em torno da marca, como fãs, profissionais do setor e possíveis compradores do produto.

\section{Papéis e hierarquias}

No contexto dos fóruns automotivos, a análise dos posts das comunidades de marca estudadas sugeriu duas dimensões fundamentais a diferenciar e hierarquizar os membros dos fóruns: (a) o conhecimento a respeito da categoria; e (b) a experiência de uso da marca/modelo em discussão na comunidade.

Sobre o primeiro tópico, em geral, ao se inserir numa comunidade dessa natureza, o internauta chega com algum grau de informação e, também, com algum grau de dúvida. Quanto mais primário é o seu conhecimento, mais as suas inseguranças se manifestam graças à baixa familiaridade com o tema em discussão na comunidade. Em outro extremo, indivíduos que demonstram ter informação sobre a categoria, aspectos técnicos e conhecimento sobre a indústria e seus players, compartilham seu conhecimento com relativo orgulho e prazer, transformando-se em uma autoridade, ainda que temporária.

O segundo pilar dessa dinâmica de clivagem se relaciona à experiência, que trata dos diferentes graus de conhecimento prático, amealhados a partir do uso da marca/modelo em questão ou, em caráter secundário, da categoria de maneira mais abrangente. O cruzamento dessas duas primeiras dimensões (informação e experiência) permite criar uma matriz de quatro quadrantes, que sugere uma tipologia de membros e de papéis que eles assumem no contexto das comunidades de marcas de automóveis investigadas na presente pesquisa:

1. Novatos (pouca informação sobre a categoria e pouca experiência com a marca/modelo): buscam a comunidade como meio de socialização/formação para o consumo de automóveis. Procuram conhecimento sobre a categoria de maneira geral e sobre a marca e o modelo em si. Em alguns casos, têm pouca experiência de uso de outros automóveis, mas não da marca/modelo que é foco das discussões da comunidade.

2. Pragmáticos (pouca informação sobre a categoria e muita experiência com a marca/modelo): são usuários da marca ou do modelo em discussão na comunidade. Podem ser compradores que realizaram escolhas emocionais (com baixo nível de informação sobre a categoria) ou meros usuários do produto (não participaram do processo de compra em si e, por isso, têm pouca informação sobre a categoria). Em alguns casos, buscam a comunidade para justificar, a posteriori, sua escolha a partir do reforço do grupo ou para compartilhar a paixão e os prazeres do uso. Entre os pragmáticos, há também os detratores da marca - consumidores que tiveram experiências ruins e desejam disseminar sua insatisfação, evitando que os demais cometam o mesmo erro (Ward \& Ostrom, 2006).

3. Teóricos (muita informação sobre a categoria e pouca experiência com a marca/modelo): usualmente, são consumidores que acumulam informação sobre a categoria ou sobre a indústria, mas não detêm conhecimento específico e experiência com a marca/modelo em debate na comunidade. Como consumidores experientes de outras marcas/modelos, podem buscar a internet como meio de adquirir experiência a partir de outrem, antes de investir na marca/modelo em questão, minimizando a percepção de risco em compras de ciclo longo e alto envolvimento, como a do automóvel (Powers, Advincula, Austin, Graiko, \& Snyder, 2012).

4. Experts (muita informação sobre a categoria e muita experiência com a marca/modelo): são líderes de opinião dentro da comunidade, ocupando posição de prestígio por conciliar tanto o conhecimento com a categoria como a experiência de uso. Em geral, são embaixadores da marca, já que consolidam sua liderança no grupo a partir do envolvimento com o produto e a comunidade. Além dos consumidores bem-informados e experientes, ocupam esse quadrante os insiders da indústria 
(funcionários da fabricante e concessionárias), ainda que a opinião destes mostre-se menos isenta, sendo passível de ser contestada pela experiência do consumidor comum e por suas impressões.

Os quatro tipos de membros e papéis estão sintetizados na Tabela 1 a seguir.

Tabela 1

Tipologia de Membros e Papéis nos Fóruns Automotivos

EXPERIÊNCIA DE USO DA MARCA/MODELO

$(-)$

\begin{tabular}{lllc}
\hline INFORMAÇÃO SOBRE A CATEGORIA & $(+)$ & Teóricos & Experts \\
& $(-)$ & Novatos & Pragmáticos \\
\hline
\end{tabular}

\section{O fórum HB20}

Constituído antes da chegada do produto às concessionárias, o fórum da HB20 reunia consumidores que tinham em comum a ausência de qualquer experiência com o produto. Assim, a análise a seguir evidencia como a comunidade evoluiu e constituiu-se desde agosto de 2012 (dois meses antes do lançamento) até abril de 2013 (seis meses após o lançamento). Nesse sentido, a possibilidade de investigar a comunidade do HB20 antes mesmo do lançamento do produto mostrou-se substancial em estratégias e narrativas não apenas sobre a fase pré-compra, mas, sobretudo, de constituição da comunidade. Trata-se, portanto, de contexto único que nos oferece um contraponto às demais comunidades abundantes em trocas de informações tanto técnicas como das práticas e hábitos de uso. Além da possibilidade de investigar motivações para integrar uma comunidade de um produto que sequer havia efetivamente chegado ao mercado brasileiro, a do HB20 nos pareceu relevante para se investigar o processo de formação e construção de hierarquia nos momentos iniciais de uma comunidade da internet a partir dos pilares de informação e experiência (descritas na Tabela 1).

\section{Pré-lançamento: um ambiente de novatos e teóricos}

O fórum Club HB20 foi criado em julho de 2011. Em setembro de 2012, portanto, um mês antes da chegada do produto às concessionárias, contava com aproximadamente 218 usuários e 329 mensagens. $\mathrm{O}$ fórum se autodenomina um clube, com o intuito de divulgar informação, compartilhar conhecimento e agregar valor a seus participantes. Apresenta-se como uma congregação de consumidores, sem vínculo institucional com a Hyundai. Em abril de 2013, observamos que a mesma comunidade já contava com 6.130 membros e quase 40 mil mensagens trocadas.

Os primeiros meses da comunidade foram marcados pela elaboração de expectativas relacionadas ao lançamento, atraindo uma massa de sujeitos que buscavam informações sobre o HB20. Como o carro ainda não havia sido lançado, tais anseios eram verbalizados com projeções mentais em formas de desejos e especulações sobre aspectos como preço, potência do motor, dúvidas em relação à rede de concessionária que venderia o produto e condições de garantia. O grupo se lançava, assim, em perguntas que iam sendo, em alguns casos, respondidas por informações amealhadas pelos integrantes, na grande imprensa, blogs e site da empresa.

A promessa contida no conceito modern premium, de um luxo acessível à maioria, parece abrir espaço na comunidade para discussões ideológicas a respeito do automóvel. Alguns participantes se detêm na discussão a respeito do direito de acesso amplo à categoria e das práticas da indústria, que terminam por elevar o preço do produto no país. Outros comentários discutem os altos impostos, que elevam o preço da categoria. Um internauta comenta que passará a andar de ônibus, como protesto à realidade do setor, ao que é rechaçado por seu interlocutor, que comenta que carros não podem ser acessíveis para a maioria (ou o trânsito das cidades seria ainda pior). O post a seguir, que especula a 
respeito do possível preço do produto, exemplifica as esperanças e discussões políticas que o lançamento abriga:

Eu acho que mesmo assim é alto, se comparamos preços lá fora que chega ser metade do nosso aqui... bem que Hyundai poderia ser a primeira a ter coragem de quebrar esse cartel das montadoras... Igual a Oi quando começou a fazer celular desbloqueado ou a Tim com planos ilimitados... Preços mais baixos, justos e carro com a mesma qualidade que eles vendem lá fora... (Marcos, 2008).

Automóveis são produtos capazes de despertar emoções (Desmet et al., 2000; Luce, 1998) e incorporar intensa dimensão simbólica (Belk, 2004; Hirschman, 2003) e ideológica (Luedicke, 2006; Luedicke \& Giesler, 2008). Nota-se que, nesse ambiente no qual não há informação oficial nem experiência concreta do produto, impressões vão circulando. Na curiosidade implícita sobre o preço, os internautas recorrem ao repertório de experiências com outras categorias e informação sobre todo o setor automotivo para elaborar um julgamento sobre as futuras ações da Hyundai, traçando cenários na tentativa de adivinhar o comportamento organizacional no mercado. O informante supramencionado parece espelhar uma esperança revolucionária relacionada ao lançamento. Por ter entrado mais recentemente no país e não se posicionar como uma das estabelecidas, a Hyundai poderia se colocar fora do cartel ou, pelo menos, com coragem de quebrá-lo, oferecendo uma oferta mais justa, com melhor preço e qualidade. O post acima evidencia, ainda, que as projeções extrapolam a simples expectativa com o produto, mas, também, consubstanciam-se no impacto que a empresa pode provocar no mercado em relação aos concorrentes, criticados e comparados com empresas de outros setores. Uma possível interpretação sugere ainda o desejo dos consumidores em expressar suas necessidades para o mercado e, talvez, influenciar o desenho da futura oferta.

A discussão dos aspectos mais políticos e ideológicos parece cumprir também outra função importante na comunidade, ao tirar a discussão a respeito da chegada do HB20 do domínio da expectativa, da emoção e ansiedade, para colocá-la no plano das ideias, da racionalidade, do direito do consumidor e do controle - valores mais afeitos à lógica masculina atrelada ao consumo do automóvel (Belk, 2004; Hirschman, 2003) e que pudemos captar nas comunidades de automóveis que investigamos. Se a experiência de uso do produto era inacessível a todos os membros da comunidade, restava aos mais engajados evidenciar a sua expertise sobre a indústria de maneira geral, posicionandose não como novatos, mas como teóricos, aqueles que detêm informações sobre a categoria e a indústria.

No período que antecede o lançamento, destaca-se ainda um esforço de diversos membros para abastecer o grupo com informações publicadas aqui e ali e provenientes de fontes de naturezas diversas. São publicados na comunidade vídeos oficiais produzidos pela Hyundai e matérias da imprensa, mas também notícias de bastidores, como a de um parente que trabalha numa concessionária da marca. Essa dinâmica de evangelização (Schau et al., 2009), com a circulação de boas notícias sobre a marca e o modelo, parece ter forte relevância no contexto anterior à chegada do produto ao mercado, já que ter alguma informação em ambiente repleto de muitas dúvidas parece ser o caminho para angariar a atenção dos membros da comunidade.

Por operar na esfera coletiva e ancorar-se nas trocas de informação subjetivas e objetivas, o fórum da HB20 se mostrou também como espaço no qual os indivíduos poderiam não apenas obter informações em primeira mão ou discutir aspectos ideológicos, mas também realizar consultas sobre cores preferidas e versões mais atraentes e até aconselhamento e debates de foro mais pessoal, como no exemplo a seguir:

Bem, moro em Brasília e aqui é tudo bem plano, carro 1.0, então, não é inconveniente aqui, pois pras minhas necessidades acho que vai bastar (também não pretendo viajar com ele). Só que eu prezo muito pelo conforto. Será que realmente vale a pena eu comprar um 1.0 comfort style? Peço a opinião de vocês pra eu poder pensar melhor, valeu. (Phelipegb, 2012).

Observa-se, neste relato, como o sujeito revela interesses de ordem subjetiva (ex.: "prezo muito pelo conforto") e objetiva (quando ele pondera os benefícios de adquirir um modelo 1.0 numa cidade plana). Ainda que o carro não tenha sido lançado, o que ele busca é a opinião e também saber o que seus 
semelhantes pensam a respeito para justificar suas escolhas futuras. Ao explicar em detalhes sua escolha (cidade plana, poucas viagens), o informante parece querer antecipar como será visto, ao comprar a versão 1.0. Há, portanto, uma construção de posicionamento sobre um conceito e marca a partir dos painéis projetivos elaborados por outros consumidores, que nem sempre conta com qualquer ação direta da empresa. O fórum torna-se, assim, um organismo vivo e interativo, modificador e mutante, que leva os informantes a modificarem-se, transformando também o valor da oferta, antes mesmo do seu lançamento. Nesse sentido, a internet se mostra como espaço no qual e ferramenta com a qual os consumidores são capazes de colaborar e coproduzir o valor de ligação da marca (Cova \& Cova, 2002), não apenas reforçando o discurso da empresa, mas gerando suas próprias interpretações de significado.

\section{O lançamento: o fim do "mistério" e a busca pelas experiências}

No dia 12 de setembro, a Hyundai realizou um evento para divulgar o lançamento do HB20 para a imprensa. Alguns membros da comunidade se esforçaram para conseguir informações restritas aos jornalistas. O interesse do grupo se concentra em aspectos como o preço e os itens incluídos no pacote de opcionais oferecido no modelo. Nesse momento, o debate político e ideológico ainda se faz presente, por exemplo, no conflito que diz respeito à forma como os participantes do fórum compreendem o conceito de carro completo. Existem aqueles que apreciariam pagar um preço mais baixo e escolher os opcionais, como é praxe das montadoras tradicionais no mercado brasileiro, e aqueles que enxergam vantagens em novas marcas que oferecem um carro a preço popular, porém completo (como o HB20).

Não gostei da Hyundai ter optado por colocar vários itens de série e com isso aumentar o preço do carro. Preferia pagar 28 contos e escolher o que colocar no carro. (Informante 1 - Carlossss, 2012).

Isso é pensamento de brasileiro mal acostumado com as nacionais. Os carros deveriam sempre vir completos para estimular a concorrência. Só acho uma pena o carro não vir com ABS. (Informante 2 - Tiago11, 2012).

Como nos lembra Slater (2002), o consumidor racional é o herói da modernidade, ao evidenciar através dos critérios sua capacidade de escolha, de guiar sua ação por uma reflexão interna (e não pelas pressões da publicidade ou da sociedade). Ainda que com lógicas distintas, os informantes 1 e 2 têm em comum o esforço de ocupar esse papel a partir do uso da razão e argumentação lógica. O que seria afinal um consumidor soberano? Aquele que tem uma oferta de melhor qualidade ou o que tem o direito de escolher aquilo que deseja? Assim, o fórum se mostra como espaço de formação e negociação, onde os internautas tentam chegar a um acordo com outros em torno do significado do carro completo e dos direitos do consumidor. A conversa é, então, finalizada com a ironia de um internauta bastante ativo na comunidade e que sugere que seu interlocutor compre um uno... simples assim.

Frustrados com o elevado preço apresentado pela Hyundai, alguns membros da comunidade lamentam a expectativa em torno da novidade, que, ao final, não se apresentou tão revolucionária, como alguns esperavam:

Estou realmente decepcionado com o resultado final do carro, sabendo como poderia ter ficado. Acho que precisarei de um viagra pra comprar esse carro pois o tesão tá indo embora.... Rsrsrs. Que pena, pois seria meu primeiro carro zero que eu teria e estava certo de que era um bom negocio... Mas pelo jeito vou ter que comprar um seminovo de boa procedência para ter itens de conforto e segurança superiores por um preço semelhante ao hb20 premiun. Fazê o que né Brasil, paisinho de m..... que aceita tudo rindo a toa!!!! (Papatella, 2012).

Um dos participantes chega a sugerir que todos os integrantes da comunidade se unam em um boicote, levando a empresa a rever sua política de preço. Porém os internautas mais engajados na comunidade antecipam o furo ao protesto e comemoram por comprar o produto antes da elevação do preço (já que antecipam o provável retumbante sucesso do novo produto). 
Legal o Boicote, esperam que consigam.... Mas pra quem quer comprar a hora é agora em outubro, pelo menos talvez consigamos algum desconto pelo IPI ainda estar baixo, porque depois que o IPI voltar ao normal, mesmo se a Hyundai manter os preços, ela não vai querer dar desconto nem a pal. Ou é caro agora ou mais caro depois... faze o quê BRASIL. Como eu to sem carro atualmente, vai ser dificil eu esperar abaixar.. se abaixar o preço... (Buzon, 2012a).

Se o caminho político e coletivo parece esvaziado pela lógica de mercado e individual, a alternativa é se engajar na discussão das ofertas apresentadas: vantagens e desvantagens relacionadas às versões 1.0 e 1.6 e do trade-off entre conforto e desempenho. O grupo também se mobiliza em exercícios de comparação com outros modelos existentes (Palio, Etios e os futuros lançamentos Onix e New Fiesta). Nas mensagens, os internautas ponderam aspectos como preço, design, acessórios e, em alguns casos, o conteúdo da publicidade. Em algumas dessas comparações, a argumentação é constituída de forma detalhada. No post em que analisa prós e contras do HB20 em relação ao Palio Sport 1.6, o internauta compara 79 itens de cada carro, destacando vantagens e desvantagens de cada modelo. Em discurso que poderia ser proferido na negociação na mesa da concessionária, o internauta termina por sugerir:

Talvez o HB20 Stylle de 43 mil fique mais pau a pau com o palio, mais ai a diferença é de 3 pau... (Emp, 2012).

No mesmo tópico, outro informante também sugere os seus itens de negociação:

Caramba, se esse HB20 tivesse teto solar incluso nesse preço de 44 mil reais NINGUEM reclamaria do preço, garanto. $\mathrm{O}$ carro realmente é lindo.... mas 44 mil é grana pakarai... (Quenison, 2012).

Os protestos, a pálida sugestão de boicote e as elucubrações a respeito do preço parecem sugerir uma expectativa de diálogo com a Hyundai, através da comunidade. Os internautas aparentam acreditar que o grupo poderia amplificar sua voz junto à montadora. Assim, a expectativa velada de ter alguma atenção da empresa e poder influenciar a sua oferta parece ser um dos elementos a motivar as discussões da comunidade.

Com a chegada do HB20 às concessionárias, as discussões do grupo se tornam menos teóricas e especulativas e mais pragmáticas. São muitas e detalhadas as histórias de visitas às lojas, registradas em fotos compartilhadas e relatos que destacam a experiência sensorial de conhecer o carro não mais apenas por fotos e vídeos, mas de verdade. São fartos e minuciosos os relatos de compra e negociação com vendedores (quanto pagou, tempo de espera, cobrança de frete, interações com os vendedores, preços dos opcionais, etc.), que atingem altos índices de visualização e respostas (esse item se mantém como o terceiro mais discutido ainda em abril de 2013). A experiência com o produto se torna capital e capaz de angariar atenções, abrindo espaço para relatos como o oferecido a seguir:

Hj fui até a loja, e já tinham os dois testes drives 1.0 e 1.6. Eu comprei o 1.6 que deve chegar até fim deste mês. Mas tive a chance e o (prazer) de dirigir o 1.0, pois o outro havia saído com outro cliente. Fiquei muito surpresa, pois o 1.0 anda muito bem. Imaginem então o 1.6.... Mas digo, aqueles que compraram o 1.0 e não dirigiram, fiquem confiantes de que ele anda muuuuito bem e com o ar 'bombando'. A dirigibilidade é maravilhosa e super macio e confortável. Amei. É isso aí. Bjs a todos. (Cmari, 2012).

Neste relato, a consumidora comprou um modelo que nem chegou a experimentar, mas ainda assim fez as suas elaborações e análises a partir de outro produto da mesma linha que ratificou seus anseios e justificou sua escolha. DaMatta et al. (2010) argumentam que existe, no contexto brasileiro, uma expectativa de diferenciação e reconhecimento de superioridade que se manifesta, em primeiro lugar, entre os que têm carro e os que não têm (pedestres) e entre os que têm carros, a partir de diferenças de preço e marcas. A fala da informante (sua empolgação nas palavras e excessos de exclamações) parece desenhar esses planos hierárquicos distintos na comunidade, mas também uma distinção entre os primeiros a ter experiência e aqueles que ainda não puderam vivenciá-la. Assim, no rol dessas hierarquias, destaca-se o item mais raro no momento de lançamento, quando o HB20 não se faz concreto 
nem mesmo para aqueles que o compraram: a experiência, o uso - uma verdadeira chance e prazer, segundo as palavras da entrevistada, mesmo que no restrito contexto do test drive.

\section{Tensões e disputas de poder e legitimidade entre teóricos e pragmáticos}

Com a entrega de alguns automóveis, os novos proprietários começam a relatar suas primeiras impressões de uso nas ruas. O primeiro post do recebimento do automóvel, entretanto, desperta a desconfiança e até a intolerância de alguns membros da comunidade. Trata-se de um internauta que se registra na comunidade e no mesmo dia se revela arrependido com a compra, devido ao alto consumo do carro. Entre as respostas recebidas, destaca-se:

Vc tá metendo o loko aí pra cima de todo mundo aqui dizendo que já está com o carro e tals... queremos ver se realmente vc está de posse da máquina mesmo, posta umas fotos aqui pra todo mundo tirar suas conclusões [do painel do computador de bordo que indica o consumo]. Não vem causando aqui não, pois este canal foi feito pra troca de informações e conhecimentos... não é um facebook da vida que vc sai, dizendo o que quer e pensa sem ao menos ter uma procedência. Eu, assim como muitos aqui, estamos 'full time' só antenados desde as especulações até o lançamento oficial... e até o momento ng recebeu o veículo... e pq vc gostosão do Morumbi já ta com o seu? Muito estranho filhão... quer ter credibilidade? Posta fotos! (Brisa, 2012).

Além da sugestão de fraude (reforçada em mensagens subsequentes com o uso do termo fakismo), a resposta acima sugere que legitimidade tem os que estão ali full time e há muito tempo. Sua fala incisiva afirma o conhecimento acumulado no grupo como um valor mais importante que a experiência de um único indivíduo sem engajamento no grupo.

Um segundo consumidor, outro recém-registrado no grupo, relata o recebimento do carro. Embora entusiasmado com a nova conquista, também é alvo de polêmica:

Uhuuuuuuuuuu Feliz da vidaaaa. Peguei o meu ontem (16/10)!!!!!!!!! Adquiri o 1.6 Premium manual - cinza titanium galera. Sinceramente, o carro é SHOW!! Lindo demais e confortável!! Realmente, quando se entra... parece ser um carro para outro nível.. Bom, espero que seja um carro formidável como aparenta ser. Seguem umas fotos para vcs admirarem huhuhuhuhuh. (TL_Sans, 2012).

Cadê as foto pow, só uma? mal tirada ainda :s [...] kkkk os cara tao de sacanagem. Se eu tivesse pegado o meu primeiro tava cheio de foto e tinha tirado as dúvidas de todos já. (Buzon, 2012b).

Acontece que nem todo mundo tem o tempo ocioso que nem o seu! Quer ver mais fotos e de melhor enquadramento?? Acesse o site do hb20.com.br. Caso contrário, compre o seu e qnd estiver com ele faça o que bem entender!!! HAAA. Quem fala o que quer.. ouve o que não quer! (TL_Sans, 2012).

Humm, tempo livre pra postar uma foto vc teve né? Estranho. Já provou o que todo mundo aki tava pensando. Tu q é um invejoso que deve ter tirado essa foto da garagem de alguém e postou aki todo paquitão (Silver Member, 2012).

kkkkkkkkkkkkkkkkkkkkkkkkk me poupe... não sou criança que nem vc para ficar inventando nada. Muito menos tenho que ficar provando qlq coisa... a foto que postei.. se parecer uma loja... me avise taa hdusahudahudahda. DESCULPE AE, se já estou com o carrão e vc não kkkkkkkkkkkkkkkkkk [...] Mas apesar da sua petulância.... espero que vc tb pegue logo seu carro! FLW. Segue mais uma fotinhaa huhuhuhuh (TL_Sans, 2012).

O informante 2 (o mesmo a sugerir a fraude no post anterior) é um dos mais ativos na comunidade, tendo se tornado moderador. Ele sugere um padrão de comportamento, criticando o colega de fórum com a falta de zelo na produção da foto e de informações mais contextualizadas ao grupo. Nesse sentido, parece exercer uma prática de administração (Schau et al., 2009), estabelecendo uma expectativa de 
comportamento, o que Muñiz e O’Guinn (2001) destacam como um senso de responsabilidade moral. Além da posição de curador capaz de julgar a qualidade do que deve ser publicado, o informante 2 valoriza o engajamento na comunidade, mas dá nome a uma emoção presente no grupo e essencial para estimular o consumo: a inveja. Ao contrário do caso anterior, em que a posição dos teóricos se manteve intacta e bem-defendida, a discussão acima parece sugerir o lugar da experiência como o mais almejado pelo grupo.

As tensões entre teóricos e pragmáticos que acontecem nesse momento chamam atenção para outro tema relevante nas comunidades de marca: a desconfiança em relação à neutralidade dos discursos. Com o produto ainda escasso no mercado, quem poderia ter a experiência do uso? Funcionários da Hyundai querendo vender o produto? Funcionários da concorrência, buscando denegri-lo?

Nessa fase inicial, muitas incertezas ainda circulam. Internautas recorrentemente ativos na defesa do novo modelo recebem no grupo o adjetivo fanboy, uma categoria negativa que pode sinalizar tanto um consumidor deslumbrado quanto um agente da empresa. Em outros casos, essa suspeita é explicitamente apresentada. Um exemplo é o do consumidor que reclamava do direito de instalar um som diferente daquele oferecido pela montadora. Na mensagem, ele ameaçava processar juridicamente a empresa. Outro participante sai, então, em defesa da montadora, alegando não haver procedência jurídica para o processo. A resposta ilustra a tensão em torno da efetiva procedência dos discursos:

Me pergunto se o caro amigo Paulo é funcionário da Hyundai... ou se apenas é mais um cidadão ignorante em relação aos seus direitos e temeroso às grandes produtoras/fornecedoras. Meu amigo, em 1990 foi promulgado no país o Código de Defesa do Consumidor, com o intuito de proteger você (será?), a parte mais fraca da relação de consumo.... Não podemos colocar um som outro que não o dela. Ok... ainda que saibamos disto... é JUSTO? HÁ EQUIDADE? Eu comprei um carro sem som porque já tenho... ou porque o da Hyundai não me agradou... e assim... terei que ficar sem som. Ou compro o dela ou me viro, faço gambiarra, perco minha garantia, corro o risco de danificar meu automóvel... é correto? ... Então amigo... por conta disso, graças ao progresso social (que é lento no nosso país) foi criado este tal código de defesa do consumidor. Caso você seja consumidor, use-o, pois nele constam os seus DIREITOS (mesmo que demorem a ser assegurados).Caso você seja um vendedor da Hyundai... tema-o, pois você o desrespeitou. (CamposBA, 2012).

Ainda que definida como uma comunidade de consumidores, sem vínculo institucional com a montadora, esses e outros posts evidenciam que os consumidores não parecem nutrir expectativas em relação à pureza do grupo. A presença das empresas (Hyundai e seus concorrentes) é tolerada, esperada e, de certa forma, valorizada pelos consumidores (mesmo sem ser explicitamente reconhecida). Ao se unir ao grupo e lançar suas opiniões no fórum, diversos internautas demonstram o anseio de tornar mais potente sua voz junto às empresas, respaldados pela atenção da audiência e possibilidade de influenciar outros internautas.

Nesse contexto, como os participantes parecem julgar as diversas falas, separando o que seria propaganda da opinião isenta de outros consumidores? A internet se apresenta como um ambiente de desconfianças, que só podem ser dirimidas pelos que têm engajamento continuado no grupo. É a presença frequente, o histórico dos participantes e o reconhecimento da consciência compartilhada no grupo (Muñiz \& O’Guinn, 2001) que permitem aos membros da comunidade separar o joio do trigo, dirimindo dúvidas e realizando uma leitura mais crítica da opinião dos outros internautas. Ou, ainda, nos termos de um dos mais ativos internautas do fórum, só aqueles que estão ali full time e antenados são capazes de desenvolver laços de verdadeira confiança com os demais integrantes do grupo.

\section{Os novos experts}

Pouco a pouco, os carros vão chegando para os membros da comunidade. Muitos comentários retratam a alegria da nova posse, algo sempre comemorado pelo grupo e alvo de muitas visualizações. Assim, a chegada de cada carro dos participantes é registrada em relatos e fotos desse momento. Esse parece se tornar um ritual do grupo (Muñiz \& O'Guinn, 2001) ou um marco seminal no consumo (Schau 
et al., 2009). Para evidenciar a importância desse conteúdo, um tópico específico é criado. Garagem, como o próprio nome sugere, reúne as experiências dos que já saíram do domínio da loja, diferenciando os que têm dos que não têm o automóvel (esse item era o segundo maior índice de visualizações, atrás apenas das dúvidas em relações ao HB20, em abril de 2013). Assim, o grupo evolui no sentido de documentação individual (Schau et al., 2009) do relacionamento com a marca.

A análise dos relatos da Garagem e sua formalização apontam para um novo plano de diferenciação na comunidade. Pouco a pouco, os relatos começam a registrar não apenas o primeiro momento, mas o processo de individualização dos automóveis, a colocação de acessórios e itens que particularizam o produto oferecido pela indústria, tornando o automóvel uma peça única e exclusiva. É interessante notar que os membros mais ativos e visualizados na comunidade têm na sua descrição de perfil e assinatura não apenas seus nomes, mas o modelo, a cor e todos os itens opcionais que constituem seu automóvel. Esse parece ser apenas o começo e um sintoma do processo de consolidação do quadrante dos experts no eixo da experiência de uso do modelo HB20 da marca Hyundai. Os líderes da comunidade são definitivamente aqueles que não só conhecem a categoria, mas finalmente circulam a bordo do tão esperado HB20.

\section{Considerações Finais}

A presente pesquisa teve por objetivo analisar o processo de formação de uma comunidade em torno de uma marca em construção (antes do seu lançamento no mercado). Para isso, utilizou-se o método netnográfico para investigar a comunidade Club HB20, criada meses antes da efetiva entrada do modelo da Hyundai em circulação.

Uma pergunta fundamental diz respeito aos fatores que podem motivar a formação de uma comunidade de marca antes mesmo do lançamento de um produto. $\mathrm{O}$ envolvimento com a categoria, o posicionamento aspiracional da marca corporativa e a expectativa de importantes mudanças no mercado a partir da oferta parecem ter ajudado a mobilizar os consumidores ainda no período de especulações sobre o lançamento. A pesquisa sugere, ainda, um olhar mais aprofundado em torno das relações que se estabelecem não apenas com a marca, mas principalmente entre consumidores e as empresas na esfera dessas comunidades. O trabalho indica que, além do interesse de obter informações, de orbitar em torno dos valores da marca ou de conectar-se com outros consumidores, os internautas investigados ansiavam por ser ouvidos pela empresa e influenciar o desenho da nova oferta. Assim, mais do que ligados aos significados (em construção) da marca, os consumidores se mostraram mobilizados pela oportunidade de cocriação desse lançamento.

A pesquisa analisa uma importante tensão que permeia as discussões da comunidade. De um lado, esta se define como um grupo de consumidores, sem ligação com a Hyundai. Parte de seu valor residiria, assim, na possibilidade de gerar conteúdo isento sobre a nova oferta. Ao mesmo tempo, nos seus discursos, os internautas sugerem a presença de participantes com uma agenda oculta (funcionários da Hyundai ou da concorrência), interessados em influenciar aquela discussão coletiva. Ainda que essa ambiguidade de papéis possa gerar certa desconfiança, ela também termina por fomentar a participação dos internautas, pois o que se fala ali tem maior potencial de chegar aos ouvidos da empresa. Assim, a pesquisa evidencia que, além da conexão com outros consumidores, a atratividade da comunidade pode residir na sua capacidade de insinuar a atenção da empresa e seus concorrentes, tornando-se um canal privilegiado através do qual consumidores se percebem como influenciadores das ofertas de mercado.

A presente pesquisa analisa como o fórum Club HB20 evolui, inicialmente, de um grupo de pessoas reunidas para troca de informações, para uma comunidade de marca, na qual existiria consciência compartilhada, rituais e tradições e um senso de responsabilidade moral (Muñiz \& O’Guinn, 2001). Assim, o trabalho oferece uma perspectiva que joga luz no processo de desenvolvimento de uma comunidade, com especial destaque para um dos pilares centrais da consciência compartilhada - a constituição da hierarquia no grupo. 
A análise sugere que essa hierarquia se constitui a partir de duas dimensões: a informação sobre a categoria e a experiência de uso com a marca/modelo em questão. A tipologia proposta distingue novatos (baixa informação e baixa experiência), teóricos (alta informação e baixa experiência), pragmáticos (baixa informação e alta experiência) e experts (alta informação e alta experiência) e destaca como essa diferenciação molda o processo de evolução da comunidade. A pesquisa evidencia, por exemplo, como as tensões e disputas de poder e legitimidade entre teóricos e pragmáticos ajudam a moldar os rituais do grupo (como as fotos e comentários na chegada do automóvel de cada membro e a constuição da seção Garagem) e a estabelecer um senso de responsabilidade moral (o tipo de imagem e informações que cada membro deve disponibilizar para os demais participantes).

O trabalho mostra ainda que, em contextos de abundância de informação, a falta desta pode motivar o boca a boca dos consumidores na internet. $\mathrm{O}$ mistério em torno desse modelo parece ter sido o combustível que abasteceu a comunidade nos seus momentos iniciais com novos integrantes, que buscavam na comunidade informações que não estavam disponíveis nas mídias convencionais. A relativa falta de informações oficiais, a um mês da chegada dos carros às concessionárias, pode ter contribuído ainda para manter o interesse em torno do grupo e oferecer uma ferramenta de distinção entre novatos e teóricos na comunidade. Enquanto os primeiros tinham pouco a contribuir com as discussões do grupo, os teóricos traziam conteúdo, reflexões sobre o setor e especulações sobre a nova oferta da Hyundai, mantendo o diálogo dos que ali participavam.

A análise evidencia como o grupo transita de um espaço exclusivamente composto por novatos e teóricos, no período de pré-lançamento, para, num segundo momento, valorizar os pragmáticos, ou seja, os primeiros consumidores a ter a efetiva experiência de uso do produto. A tensão entre teóricos (os que tinham informação, mas não o carro) e pragmáticos (os que já eram proprietários), na hierarquia do grupo, também parece ter servido como estímulo adicional para a aquisição do produto pelos membros da comunidade. Nesse aspecto, o trabalho pode servir de inspiração para gestores que têm o desafio de promover a experimentação de seus lançamentos.

Por fim, com a chegada mais ampla do HB20 às ruas, o grupo evolui para a personalização dos automóveis, a partir da colocação de itens opcionais e especiais, como meio de tangibilizar a posição de experts, ou seja, de membros que detêm não apenas informação, mas também a experiência distintiva na comunidade.

Ao realizar uma análise que contempla não apenas a circulação da informação, mas também desenha lógicas que estruturam diferenciação e movimentam as emoções dos seus integrantes, o presente trabalho oferece instrumentos para ajudar gestores na tarefa de se relacionar com as comunidades virtuais no processo de lançamento de novos produtos. O trabalho também descreve como o grupo assimila as frustrações ante o que era esperado, gerencia sua própria expectativa e contorna as críticas ao produto. Nesse sentido, ele oferece um repertório de práticas a serem analisadas pelos profissionais do setor.

Estudos futuros podem buscar confrontar a tipologia e as dinâmicas aqui descritas à luz de outros contextos e categorias de produtos. Um aspecto apenas tangenciado na presente pesquisa diz respeito ao comportamento de resistência e boicote, bem como a internet como espaço de negociação de ideologias. $\mathrm{Na}$ presente pesquisa, a frustração com o alto preço do HB20 não foi capaz de mobilizar um boicote, como chegou a ser sugerido por alguns integrantes do grupo. Ao mesmo tempo em que a internet expande o poder do consumidor e cria uma consciência coletiva, a mobilização efetiva ainda parece ser frágil no domínio das comunidades de marca e restrita aos sites e ações de ciberativistas (McCaughey \& Ayers, 2003). Assim, um tema para estudos futuros diz respeito a como os argumentos anticonsumistas são assimilados pelas comunidades de marca. 


\section{Referências}

Algesheimer, R., Dholakia, U. M., \& Herrmann, A. (2005). The social influence of brand community: evidence from European car clubs. Journal of Marketing, 69(3), 19-34. doi: $10.1509 /$ jmkg.69.3.19.66363

Almeida, T. N. V., \& Ramos, A. S. M. (2012). Os impactos das reclamações on-line na lealdade dos consumidores: um estudo experimental. Revista de Administração Contemporânea, 16(5), 664683. Recuperado de http://www.scielo.br/readcube/epdf.php?doi=10.1590/S1415$65552012000500003 \&$ pid=S1415-

65552012000500003\&pdf_path=rac/v16n5/v16n5a03.pdf\&lang=pt. doi: 10.1590/S141565552012000500003

Belk, R. W. (2004). Men and their machines. Advances in Consumer Research, 31(1), 273-278.

Brisa, M. (2012, julho 23). Re: Comprei, mas me arrependi [Comentário em fórum online]. Recuperado de http://hb20clube.com.br/viewtopic.php?f=5\&t=431\&start=10

Brown, S., Kozinets, R. V., \& Sherry, J. F., Jr. (2003). Teaching old brands new tricks: retro branding and the revival of brand meaning. Journal of Marketing, 67(3), 19-33. doi: 10.1509/jmkg.67.3.19.18657

Buzon (2012b, setembro 18). Re: Já esta em minha garagem. [Comentário em fórum online]. Recuperado de http://hb20clube.com.br/viewtopic.php?f=5\&t=479

Buzon (2012a, setembro 17). Re: Vamos boicotar o HB20 agora, que eles baixam os preços! !!! [Comentário em fórum online]. http://hb20clube.com.br/viewtopic.php?f=5\&t=284\&start=10

CamposBA (2012, setembro 8). Re: Central multimídia [Comentário em fórum online]. Recuperado de http://www.hb20sclube.com.br/viewtopic.php?f=7\&t=601\&start=10

Carlossss (2012, setembro 16). Carro pelado seria melhor. [Tópico em fórum online]. Recuperado de http://hb20clube.com.br/viewtopic.php?f=10\&t=282

Cmari (2012, outubro 11). Teste drive em Florianopolis -eu fiz!!! [Tópico em fórum online]. Recuperado de http://hb20clube.com.br/viewtopic.php?f=10\&t=498

Cova, B., \& Cova, V. (2002). Tribal marketing: the tribalisation of society and its impact on the conduct of marketing. European Journal of Marketing, 36(5/6), 595-620. doi: $10.1108 / 03090560210423023$

Cova, B., \& Pace, S. (2006). Brand community of convenience products: new forms of customer empowerment - the case "my Nutella The Community". European Journal of Marketing, 40(9/10), 1087-1105. doi: 10.1108/03090560610681023

Cova, B., \& White, T. (2010). Counter-brand and alter-brand communities: the impact of web 2.0 on tribal marketing approaches. Journal of Marketing Management, 26(3/4), 256-270. doi: $10.1080 / 02672570903566276$

DaMatta, R., Vasconcelos, J. G., \& Pandolfi, R. (2010). Fé em Deus e pé na tábua, ou como e por que o trânsito enlouquece no Brasil. Rio de Janeiro: Rocco.

Desmet, P. A., Hekkert, P. P., \& Jacobs, J. J. (2000). When a car makes you smile: development and application of an instrument to measure product emotions. Advances in Consumer Research, 27(1), 111-117. 
Emp, C. (2012, setembro 23). Palio X HB [Tópico em fórum online]. Recuperado de http://hb20clube.com.br/viewtopic.php? $\mathrm{f}=13 \& \mathrm{t}=309 \&$ start $=0$

Federação Nacional da Distribuição de Veículos Automotores. (2013). Mais vendidos. Recuperado de http://www3.fenabrave.org.br:8082/plus/modulos/listas/index.php?tac=indices-enumeros\&idtipo $=1 \&$ layout $=$ indices-e-numeros

Hernandez, J. M. C. (2002). Um estudo empírico sobre os benefícios da procura e do uso da internet como fonte de informações. Revista de Administração Contemporânea, 6(3), 149-173. doi: $10.1590 / \mathrm{S} 1415-65552002000300009$

Hirschman, E. C. (2003). Men, dogs, guns and cars: the semiotics of rugged individualism. Journal of Advertising, 32(1), 9-22. doi: 10.1080/00913367.2003.10601001

Hollenbeck, C., \& Zinkhan, G. (2010). Anti-brands communities, negotiation of brand meaning, and the learning process: the case of Wal-Mart. Consumption Markets and Culture, 13(3), 325-345. doi: $10.1080 / 10253861003787056$

Instituto Brasileiro de Opinião Pública e Estatística. (2013). Anunciantes - 30 maiores - 2012 - ano. Recuperado de http://www.ibope.com.br/ptbr/conhecimento/TabelasMidia/investimentopublicitario/Paginas/ANUNCIANTES---30MAIORES---2012---ANO.aspx

Kozinets, R. V. (2010). Netnography: doing ethnographic research online. London: Sage Publications.

Kozinets, R. V., \& Handelman, J. M. (2004). Adversaries of consumption: consumer movements, activism, and ideology. Journal of Consumer Research , 31(3), 691-704. doi: 10.1086/425104

Kozinets, R. V., Valck, K., Wojnicki, A., \& Wilner, S. (2010). Networked narratives: understanding word-of-mouth marketing in online communities. Journal of Marketing, 74(2), 71-89. doi: 10.1509/jmkg.74.2.71

Luce, M. (1998). Choosing to avoid: coping with negatively emotion-laden consumer decisions. Journal of Consumer Research, 24(4), 409-433. doi: 10.1086/209518

Luedicke, M. K. (2006). Brand community under fire: the role of social environments for the HUMMER Brand Community. Advances in Consumer Research, 33(1), 486-493.

Luedicke, M. K., \& Giesler, M. (2008). Contested consumption in everyday life. Advances in Consumer Research, 35(1), 812-813.

Marcos (2008, agosto 8). Re: Hyundai HB20 e seu verdadeiro preço [Comentário em fórum online]. Recuperado de http://hb20clube.com.br/viewtopic.php?f=7\&t=166

McCaughey, M., \& Ayers, M. D. (2003). Cyberactivism: online activism in theory and practice. New York: Routledge.

McCracken, G. (2003). Cultura e consumo. Rio de Janeiro: Mauad.

Miles, M. B., Huberman, A. M., \& Saldaña, J. (2013). Qualitative data analysis: a methods sourcebook. Thousand Oaks, CA: Sage.

Muñiz, A. M., Jr., \& O’Guinn, T. C. (2001). Brand community. Journal of Consumer Research, 27(4), 412-433.

Muñiz, A. M., Jr., \& Schau, H. J. (2005). Religiosity in the abandoned apple newton brand community. Journal of Consumer Research, 31(4), 737-747. doi: 10.1086/426607 
O'Sullivan, S., Richardson, B., \& Collins, A. (2011). How brand communities emerge: the beamish conversion experience. Journal of Marketing Management, 27(1), 891-912. doi: $10.1080 / 0267257 X .2011 .565684$

Papatella, R. (2012, setembro 18). Re: Projeto do hb20 era melhor que a versão final!!! [Comentário em fórum online]. Recuperado de http://hb20clube.com.br/viewtopic.php?f=5\&t=298

Phelipegb (2012, abril 10). Vale a pena comprar o HB20 1.0 comfort style?? [Tópico em fórum online]. Recuperado de http://hb20clube.com.br/viewtopic.php?f=7\&t=283

Powers, T., Advincula, D., Austin, M. S., Graiko, S., \& Snyder J. (2012). Digital and social media in the purchase decision process. Journal of Advertising Research, 52(4), 479-489. doi: 10.2501/JAR-52-4-479-489

Quatro Rodas. (n.d.). Como funciona a tabela FIPE. Recuperado de http://quatrorodas.abril.com.br/tabela-de-precos/

Quenison (2012, setembro 23). Re: Palio X HB [Comentário em fórum online]. Recuperado de http://hb20clube.com.br/viewtopic.php?f=13\&t=309\&start=0

Rheingold, H. (1993). The virtual community: homesteading on the electronic frontier. Reading, MA: Addison-Wesley.

Sastre, P. T. N., Serralvo, F. A., \& Moras, A. C. (2010, setembro). A influência dos grupos de referência no processo decisório do consumidor: um estudo no segmento de veículos utilitários esportivos. Anais do Encontro Nacional da Associação Nacional de Pós-Graduação e Pesquisa em Administração, Florianópolis, SC, Brasil, 4.

Scaraboto, D., Vargas, C. A., \& Costa, D. (2012). How consumers persuade each other: rhetorical strategies of interpersonal influence in online communities. Brazilian Administration Review, 9(3), 246-267. Retrieved from http://www.scielo.br/pdf/bar/v9n3/a02v9n3.pdf. doi: $10.1590 / \mathrm{S} 1807-76922012000300002$

Schau, H., Muñiz, A. M., Jr., \& Arnould, E. (2009). How brand community practices create value. Journal of Marketing, 73(5), 30-51. doi: 10.1509/jmkg.73.5.30

Schellekens, G. A., Verlegh, P. W. J., \& Smidts, A. (2010). Language abstraction in word of mouth. Journal of Consumer Research, 37(2), 207-223. doi: 10.1086/651240

Silver Member (2012, agosto 21). Re: Já esta em minha garagem [Comentário em fórum online]. Recuperado de http://hb20clube.com.br/viewtopic.php?f=5\&t=479

Slater, D. (2002). Consumer culture \& modernity. Oxford: Blackwell Publishing.

Suarez, M., Chauvel, M. A., \& Casotti, L. (2012). Motivações e significados do abandono de categoria: aprendizados a partir da investigação com ex-fumantes e ex-proprietários de automóveis. Cadernos EBAPE.BR, 10(2), 411-434. doi: 10.1590/S1679-39512012000200010

Tiago11 (2012, setembro 16). Re: carro pelado seria melhor [Comentário em fórum online]. Recuperado de http://hb20clube.com.br/viewtopic.php?f=10\&t=282

Thompson, C. J., Pollio, H. R., \& Locander, W. B. (1994). The spoken and the unspoken: a hermeneutic approach to understanding the cultural viewpoints that underlie consumers' expressed meanings. Journal of Consumer Research, 21(3), 432-452. doi: 10.1086/209409

Thompson, S. A., \& Sinha, R. K. (2008). Brand communities and new product adoption: the influence and limits of oppositional loyalty. Journal of Marketing, 72(6), 65-80. doi: 10.1509/jmkg.72.6.65 
TL_Sans (2012, outubro 17). Re: Alguém já pegou o hb20 [Comentário em fórum online]. Recuperado de http://hb20sclube.com.br/viewtopic.php?f=5\&t=450\&view=previous

Ward, J. C., \& Ostrom, A. L. (2006). Complaining to the masses: the role of protest framing in customercreated complaint web sites. Journal of Consumer Research, 33(2), 220-230. doi: $10.1086 / 506303$

Yeh, Y., \& Choi, S. (2011). MINI-lovers, maxi-mouths: an investigation of antecedents to eWOM intention among brand community members. Journal of Marketing Communications, 17(3), 145162. doi: $10.1080 / 13527260903351119$

Zhu, R., Chen, X., \& Dasgupta, S. (2008). Can trade-ins hurt you? Exploring the effect of a trade-in on consumers' willingness to pay for a new product. Journal of Marketing Research, 45(2), 159170. doi: 10.1509/jmkr.45.2.159

\title{
Dados dos Autores
}

\author{
Maribel Carvalho Suarez \\ Rua Paschoal Lemme, 355, Ilha do Fundão, 21941-918, Rio de Janeiro, RJ, Brasil. E-mail: maribels@ coppead.ufrj.br \\ Flavia Luzia Oliveira da Cunha Galindo \\ Rodovia BR 465, Km 7, Campus Universitário, Zona Rural, 23851-970, Seropédica, RJ, Brasil. E-mail: \\ flaviagalindo@uol.com.br \\ Vaclav Soukup Filho \\ Rua Paschoal Lemme, 355, Ilha do Fundão, 21941-918, Rio de Janeiro, RJ, Brasil. E-mail: vaclavfilho@ yahoo.com.br \\ Rafael Machado \\ Rua Paschoal Lemme, 355, Ilha do Fundão, 21941-918, Rio de Janeiro, RJ, Brasil. E-mail: ferreiramachado.rafael@ gmail.com
}

